\title{
An Ascorbate-Mediated Transmembrane-Reducing System of the Human Erythrocyte
}

\author{
Eugene P. Orringer and Marjorie E. S. Roer, Division of Hematology, Departments \\ of Medicine and Laboratory Medicine, University of North Carolina School of \\ Medicine, Chapel Hill, North Carolina 27514
}

\begin{abstract}
A B S T R A C T Actively metabolizing human erythrocytes catalyze the extracellular reduction of ferricyanide to ferrocyanide. Because neither of these anions can enter the cell, reducing equivalents generated in the course of glycolysis must in some manner be transferred across the cell membrane, thereby resulting in ferricyanide reduction. Work described in this paper suggests that the transmembrane reduction is effected by ascorbic acid. This compound in its oxidized form (dehydroascorbate) rapidly enters the cell. Here it obtains reducing equivalents which appear to come from NADH made available at the level of glyceraldehyde 3-phosphate dehydrogenase. Once reduced, it leaves the cell as ascorbic acid and accomplishes the nonenzymatic reduction of ferricyanide.
\end{abstract}

\section{INTRODUCTION}

Ferricyanide $\left[\mathrm{Fe}(\mathrm{CN})_{6}\right]^{-3}$, an anionic species carrying three negative charges, can be reduced to ferrocyanide $\left[\mathrm{Fe}(\mathrm{CN})_{6}\right]^{-4}$ by human erythrocytes $(\mathrm{RBC})^{1}(1,2)$. If the RBC are deprived of metabolic substrate or exposed to an inhibitor such as iodoacetate, the rate of ferrocyanide generation is slowed (2). Because of their size and hydrophilic nature neither ferricyanide nor ferrocyanide can cross the cell membrane (3). It has therefore been presumed that reducing equivalents generated in the course of glycolysis are somehow transferred across the membrane.

We have examined the RBC-mediated ferricyanide reduction system with both intact $\mathrm{RBC}$ and resealed ghost preparations. Our results suggest that NADH generated at the glyceraldehyde 3-phosphate dehydrogenase (G3PD) reaction is the primary source of reduc-

A portion of this work has been published in abstract form (1).

Received for publication 22 May 1978 and in revised form 18 September 1978.

${ }^{1}$ Abbreviations used in this paper: AA, ascorbic acid; DHA, Dehydroascorbate; G3PD, glyceraldehyde 3-phosphate dehydrogenase; $\mathrm{Pi}$, inorganic phosphorous; RBC, human erythrocytes. ing equivalents, that ascorbate carries them across the cell membrane, and that ferricyanide is the final acceptor in the system.

\section{METHODS}

Venous blood was drawn into heparin-rinsed syringes from normal volunteers just before each study. Samples were obtained from chronic hemodialysis patients immediately before the dialysis procedure. Because the uptake of ascorbate by leukocytes is 40 times more rapid than by RBC (4), the RBC were washed in cold $\mathrm{NaCl} 165 \mathrm{mM}(305 \operatorname{mosM})$ with the careful removal by aspiration of plasma, buffy coat, and uppermost RBC layers. The final ratio of RBC:leukocytes in the incubation flasks always exceeded 1,000.

Preincubations were carried out in plasma or in a "preincubation medium" which contained $\mathrm{NaCl} 140 \mathrm{mM}, \mathrm{NaHCO}_{3}$ $25 \mathrm{mM}$, and glucose $10 \mathrm{mM}$. The flasks were gently swirled in a humidified atmosphere of $95 \% \mathrm{O}_{2}$ and $5 \% \mathrm{CO}_{2}$ for $10 \mathrm{~min}$ before the preincubation was begun. The $\mathrm{pH}$ of the cell suspensions was $7.30-7.35$ at $37^{\circ} \mathrm{C}$. After the preincubation the $\mathrm{RBC}$ were again washed in physiological saline.

All ferrocyanide generation experiments were performed in the "standard medium" which contained $\mathrm{NaCl} 100 \mathrm{mM}$, $\mathrm{KCl} 5 \mathrm{mM}, \mathrm{Na}_{2} \mathrm{HPO}_{4} 20 \mathrm{mM}$, glycylglycine $10 \mathrm{mM}$, and glucose $10 \mathrm{mM}$. Dehydroascorbate (DHA) was added to the indicated flasks. The final $\mathrm{pH}$ was adjusted to 7.4 at $25^{\circ} \mathrm{C}$., after which the RBC were included. The suspension was then warmed to $37^{\circ} \mathrm{C}$. for $5 \mathrm{~min}$, after which sufficient $\mathrm{K}_{3} \mathrm{Fe}(\mathrm{CN})_{6}$ was added to give a final concentration of $1 \mathrm{mM}$. Samples were taken at $0,10,20$, and $30 \mathrm{~min}$, placed immediately at $0^{\circ} \mathrm{C}$ in a refrigerated centrifuge, and spun for $5 \mathrm{~min}$ at $12,062 \mathrm{~g}$. The supernate was carefully removed from the cell button by Pasteur pipette and assayed for ferrocyanide.

All incubations were performed in stoppered flasks at $37^{\circ} \mathrm{C}$ in a water bath shaker set at 100 oscillations/min over a 1 -inch traverse. In both preincubation and ferrocyanide generation studies the cell:medium ratio was $1: 10-1: 20$, and the total volume in each flask was $10 \mathrm{ml}$. RBC counts were performed using a model S Coulter counter (Coulter Electronics Inc., Hialeah, Fla.).

Ferrocyanide quantitation was performed using the phenanthroline complex as described by Avron and Shavit (5). For the assay, $100 \mu \mathrm{l}$ of sample was diluted with distilled water to a 1.4-ml final volume. By this method a concentration of ferrocyanide as low as $1 \mu \mathrm{M}$ can be accurately quantitated. Further, no effect of excess ferricyanide was observed on this assay system.

Resealed ghosts were prepared by a slight modification of 
published methods $(6,7)$. Hypotonic lysis and reversal were carried out at $0^{\circ} \mathrm{C}$ in a thermostated beaker with a magnetic stirrer. Both temperature and $\mathrm{pH}$ were monitored continuously. Freshly drawn RBC were washed twice with cold unbuffered $\mathrm{NaCl}(165 \mathrm{mM})$, resuspended in this same medium at an hematocrit of $50 \%$, and cooled on salted ice. 1 vol of cold RBC suspension was then added to $10 \mathrm{vol}$ of hemolyzing medium which contained (millimolar): $\mathrm{MgSO}_{4} 4$, acetic acid 3.8, and ATP 0.5. Also added at this time were other metabolites which were to be incorporated into the ghost systems. Their concentrations are detailed in the appropriate figure legends. The $\mathrm{pH}$ of the lysate, measured at $0^{\circ} \mathrm{C}$ was $5.8-$ 6.2. After $5 \mathrm{~min}$ at $0^{\circ} \mathrm{C} 1 \mathrm{vol}$ (equal to the volume of RBC suspension originally added to the hemolyzing medium) of icecold reconstituting medium (KCl $1990 \mathrm{mM}$, Tris-OH $25 \mathrm{mM}$ ) was added, after which the $\mathrm{pH}$ of the hemolysate rose to 7.0-7.3. After a further $10 \mathrm{~min}$ at $0^{\circ} \mathrm{C}$ the entire hemolysate was removed from the $0^{\circ} \mathrm{C}$ beaker and transferred to a $37^{\circ} \mathrm{C}$ flask for resealing. After a 45 -min incubation at $37^{\circ} \mathrm{C}$, the resealed ghosts were removed and washed four times in a wash solution containing $\mathrm{NaCl} 165 \mathrm{mM}$ and Tris-OH $2 \mathrm{mM}$, buffered to $\mathrm{pH} 7.4$ at $25^{\circ} \mathrm{C}$. The ghosts were now ready for use in the experimental protocols.

ATP was assayed fluorometrically as detailed by Lowry et al. (8). Neutralized perchloric acid extracts for this determination were prepared according to Orringer and Mattern (9). Total ascorbate in the plasma of dialysis and control subjects was measured according to Owen and Iggo (10).

Data presented in Table $I$ and Fig. 6 are expressed as the mean \pm 1 SD. The remainder of the figures are representative experiments, each of which has been repeated on multiple occasions.

\section{RESULTS}

The initial rate of ferricyanide reduction by fresh RBC is $\cong 5 \mathrm{mmol} /$ liter $\mathrm{RBC} \cdot \mathrm{h}$. After $30 \mathrm{~min}$ of incubation, however, this rate slows appreciably $(1,12)$. We noted that $\mathrm{RBC}$ which had spent $2 \mathrm{~h}$ at $37^{\circ} \mathrm{C}$ in the preincubation medium before exposure to ferricyanide also

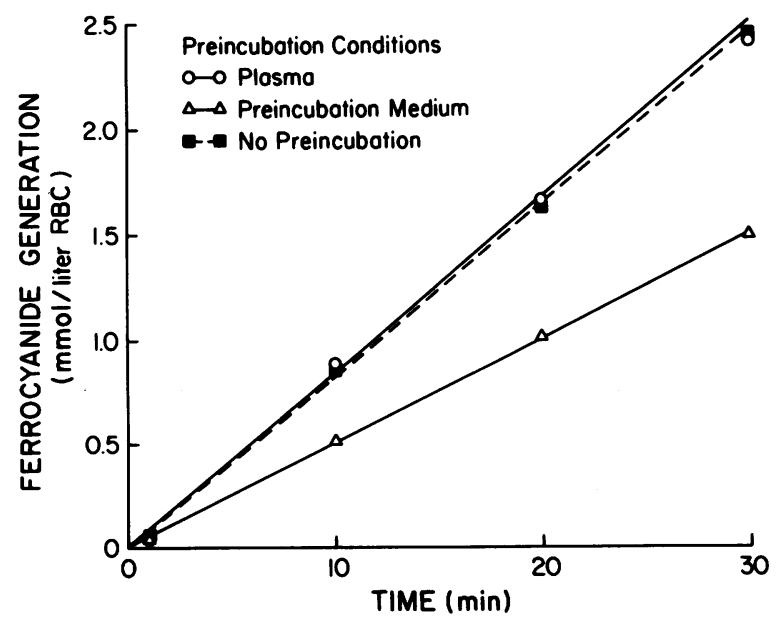

FIGURE 1 Ferrocyanide generation by RBC preincubated in plasma or preincubation medium for $2 \mathrm{~h}$ before ferricyanide exposure. The rate of ferrocyanide generation by fresh $\mathrm{RBC}$ is shown for comparison. generated ferrocyanide slowly, while $\mathrm{RBC}$ which had undergone a similar $2 \mathrm{~h}$ preincubation in plasma reduced ferricyanide as well as fresh RBC (Fig. 1). This experiment suggested that a "plasma factor" might be of some importance in the reduction of ferricyanide.

Ferrocyanide generation by RBC from normal donors was next compared to that demonstrated by RBC from chronic hemodialysis subjects. The cells from this latter group reduced ferricyanide at a significantly higher rate (Table I). To determine whether the accelerated ferrocyanide generation observed resulted from an intrinsic difference in the hemodialysis RBC or an increase in the plasma factor noted in the previous experiment, the following study was performed. RBC from a normal subject were separated from plasma, washed, and divided into two lots. These RBC were then preincubated in $\mathrm{ABO}$-compatible plasma from either a hemodialysis or a normal donor. After a 2-h preincubation, the cells were washed free of plasma and exposed to ferricyanide. The hemodialysis plasma was able to confer the increased capacity for ferrocyanide generation onto the normal RBC (Table II).

The next group of studies were designed to characterize further the plasma factor. A careful review of our dialysis population revealed that each patient was given daily one Tabron tablet (Parke, Davis \& Co., Detroit, Mich.), a multivitamin preparation which contains $500 \mathrm{mg}$ of ascorbic acid (AA). Patients on chronic dialysis are supplemented with vitamin $C$ because it is dialyzable, and AA depletion is known to occur (11, 12). When large oral doses $(250-500 \mathrm{mg} / \mathrm{d})$ are given, predialysis plasma AA levels have been invariably high (13). To confirm this observation, plasma ascorbate was measured in several of our dialysis and control subjects. In each case the plasma ascorbate level in the dialysis subjects exceeded that in the control population by close to an order of magnitude (dialysis subjects 100-250 $\mu \mathrm{M}$; control 15-30 $\mu \mathrm{M}$ ). Further those dialysis subjects with the highest AA levels also had the highest rate of ferrocyanide generation. This information coupled with the ability of ascorbate to enter the RBC led us to postulate that AA might be the plasma factor. The standard midpoint redox potentials for the couples ferri-/ferrocyanide and dehydroascorbate/ascorbate are respectively 0.36 and $0.058 \mathrm{~V}$. Thus, the

TABLE I

Ferrocyanide Generation by RBC from Chronic Hemodialysis Patients and Normal Donors

\begin{tabular}{ccc}
\hline & Normal & Hemodialysis \\
\hline Ferrocyanide generation* & $\begin{array}{c}5.5 \pm 0.7 \ddagger \\
n=14\end{array}$ & $\begin{array}{c}14.5 \pm 4.5 \ddagger \\
n=12\end{array}$
\end{tabular}

* Expressed as $\mathrm{mmol} / \mathrm{liter} \mathrm{RBC} \cdot \mathrm{h}$.

$\$$ Mean \pm 1 SD. 
TABLE II

Ferrocyanide Generation by RBC* After Preincubation in Normal or Hemodialysis Plasma

\begin{tabular}{lc}
\hline Preincubation plasma & Ferrocyanide generation $\mathbb{}$ \\
\hline Normal & 4.4 \\
Hemodialysis & 12.0
\end{tabular}

* Fresh RBC which were ABO-compatible with both the normal and the hemodialysis plasma, were obtained from a third, independent donor.

\# Expressed as $\mathrm{mmol} /$ liter $\mathrm{RBC} \cdot \mathrm{h}$.

reduction of ferricyanide by ascorbate is thermodynamically favored and has a standard free energy of $-8,000 \mathrm{cal} / \mathrm{mol}$ (14). When mixed together, each mole of AA instantaneously generated 2 mol of ferrocyanide (Fig. 2). The reduction of ferricyanide was, therefore, accomplished by the oxidation of $\mathrm{AA}$ to DHA, a reaction that generated two reducing equivalents. Because the RBC contains a mechanism for DHA reduction $(15,16)$, a simple experiment was next designed in which DHA was added to the preincubation medium. If DHA at a physiological concentration (17) could prevent the decline in ferrocyanide generation otherwise observed after preincubation, one could make a strong case for the role of ascorbate as the plasma factor. As shown in Fig. 3, cells exposed to preincubation medium containing $50 \mu \mathrm{M}$ DHA, reduced ferricyanide as well as cells preincubated in plasma.

Ferrocyanide generation was next examined in the presence of DHA. Two sets of flasks were prepared, each containing the standard medium and graded concentrations of DHA. The first group of flasks contained

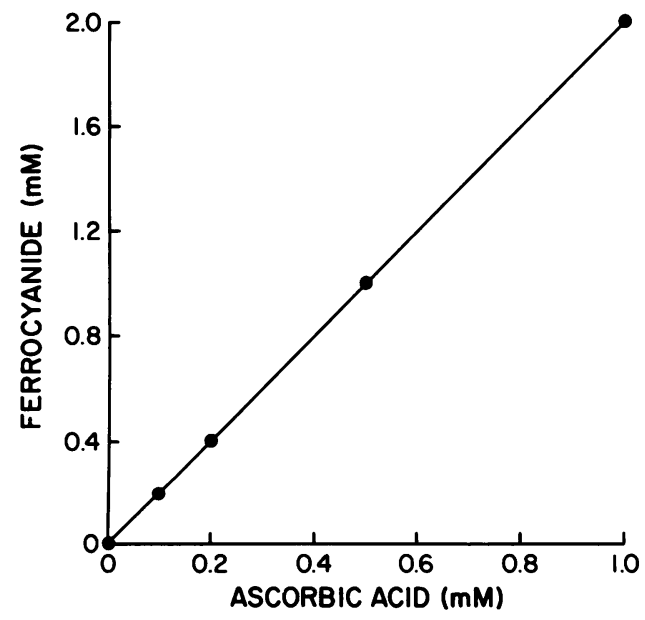

FIGURE 2 The instantaneous conversion of ferri $\rightarrow$ ferro by the addition of various amounts of AA. Each mole of AA reduced $2 \mathrm{~mol}$ of ferricyanide. (See text for details.)

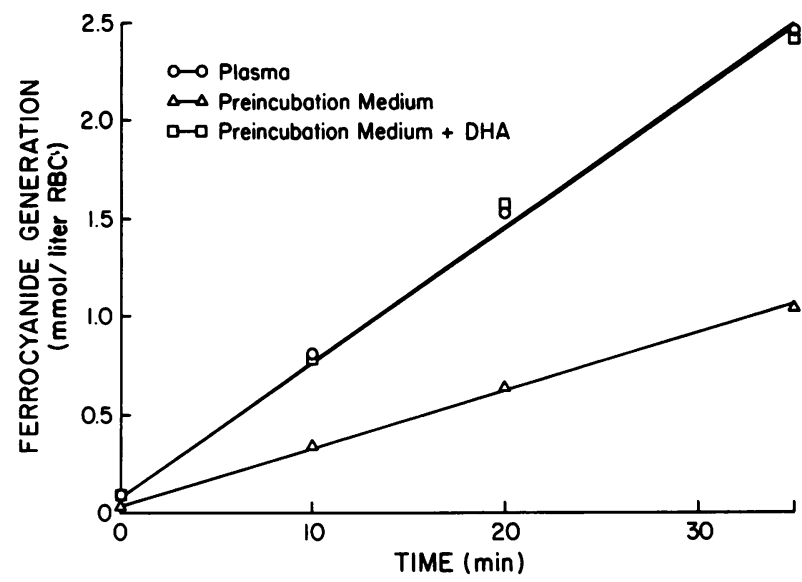

Figure 3 Ferricyanide reduction by RBC after a 2-h preincubation in: (a) plasma; (b) preincubation medium; or $(c)$ preincubation medium plus DHA $(50 \mu \mathrm{M})$.

$10^{12} \mathrm{RBC} /$ liter suspension whereas no $\mathrm{RBC}$ were present in the second set of flasks. The rate of ferrocyanide generation was then expressed as a function of the DHA concentration (Fig. 4). In the absence of RBC, little ferrocyanide appeared until the concentration of DHA exceeded $0.1 \mathrm{mM}$, and above this amount the rate of ferricyanide reduction appeared to be a linear function of the DHA concentration in the flask. In the presence of RBC, however, as little as $10 \mu \mathrm{M}$ DHA exhibited a pronounced effect on the rate of ferricyanide reduction. Unlike the linear relationship observed with DHA alone, the ferricyanide reduction effected by the cells in the presence of DHA appeared to be a saturable function of the concentration of DHA. The additional ferricyanide reduction in this set of flasks at DHA concentrations exceeding $0.1 \mathrm{mM}$ was accounted for almost

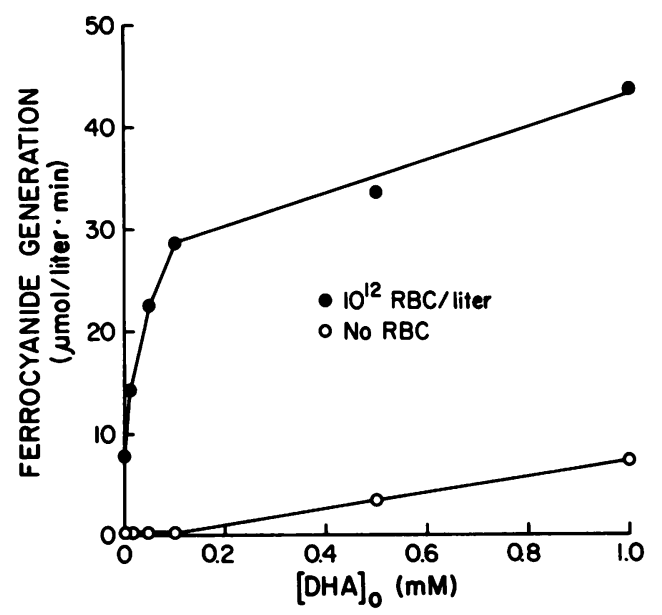

FIGURE 4 Ferrocyanide generation $(\mu \mathrm{mol} / \mathrm{liter} \cdot \mathrm{min})$ in the absence or presence of RBC (102/liter suspension) expressed as a function of the DHA concentration in the flask. 
entirely by the direct interaction between DHA and ferricyanide.

The remaining experiments were designed to clarify the mechanism by which cellular DHA reduction (and ultimately ferrocyanide generation) occurred. Several lines of evidence suggested that the availability of NADH might be the critical determinant of DHA reduction. First, a direct relationship between the rate of ferricyanide reduction and the concentration of inorganic phosphorous $(\mathrm{Pi})$ in the flask supported this hypothesis, since the rate of the G3PD reaction can be modulated by the concentration of $\mathrm{Pi}(18)$, and the availability of NADH is in turn dependent on the rate of the G3PD reaction. Second, the inclusion of pyruvate, an oxidant of NADH, slowed the rate of ferrocyanide generation. Third, G6PD-deficient subjects (both mild and severe variants) reduce ferricyanide as well as normal cells. In fact fresh RBC from a G6PDdeficient child with congenital nonspherocytic hemolysis exhibited an accelerated rate of ferrocyanide generation $(8.5 \mathrm{mmol} / \mathrm{liter} \mathrm{RBC} \cdot \mathrm{h})$ vs. a simultaneous control subject $(4.5 \mathrm{mmol} /$ liter $\mathrm{RBC} \cdot \mathrm{h})$.

The resealed ghost technique was used for the last studies. The absence of methemoglobin formation after ferricyanide exposure indicated that the ghosts were all tightly sealed to both hemoglobin and ferricyanide. The data presented in Fig. 5 represent the cumulative results of several experiments. All three ghost systems were prepared simultaneously with RBC obtained from the same donor. As is evident, the presence of an NADH-generating system increased the rate of ferrocyanide generation. Although resealed ghosts are not totally devoid of any component present in intact RBC, the next experiment was designed to demonstrate the

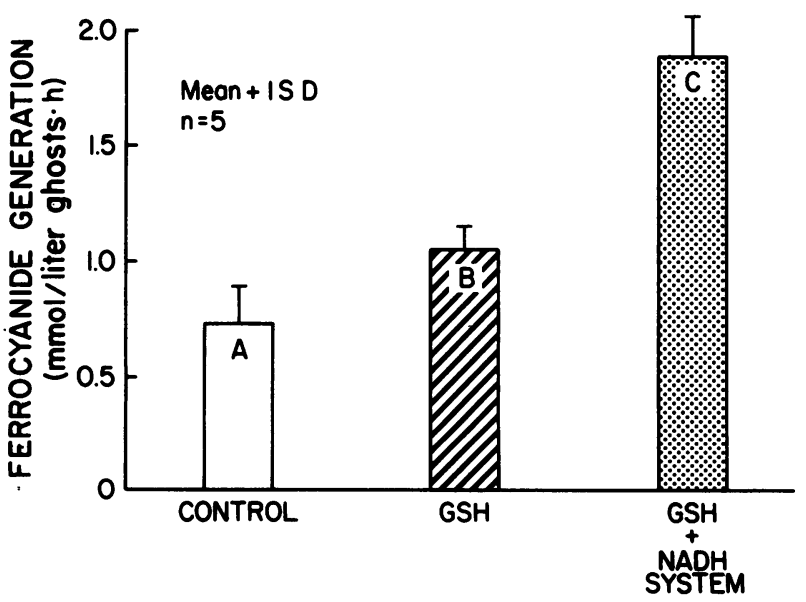

FIGURE 5 Ferrocyanide generation (mmol/liter ghosts $\cdot h$ ) by resealed ghost preparations. Metabolic intermediates and enzymes within the ghosts included: (A) ATP $0.5 \mathrm{mM}$; (B) ATP $0.5 \mathrm{mM}$, GSH $1.0 \mathrm{mM}$; (C) ATP $0.5 \mathrm{mM}$, GSH $1.0 \mathrm{mM}$, NAD $0.25 \mathrm{mM}$, fructose diphosphate $0.5 \mathrm{mM}$, ADP $0.25 \mathrm{mM}$, nicotinamide $0.5 \mathrm{mM}$, aldolase $0.03 \mathrm{mg}$, G3PD $0.3 \mathrm{mg}$. All flasks contained DHA $(50 \mu \mathrm{M})$. importance of adequate amounts of NAD and $\mathrm{Pi}$, two of the metabolites required for the G3PD reaction. In this study ghosts containing the entire NADH system were compared to those having all additives except NAD, and the rate of ferricyanide reduction by these two groups was examined in the presence and absence of $\mathrm{Pi}$. The data indicated the importance of the complete system (Fig. 6). Finally, the dependence on both NADH and DHA in the ghost system is shown on Table III. The rate of ferricyanide reduction observed in the presence of the entire system (NADH plus DHA) is far greater than the sum of the rates seen individually.

\section{DISCUSSION}

The cell membrane presents an impenetrable barrier to the movement of ferricyanide (3). Therefore the demonstration that ferricyanide, when added to a RBC suspension, could induce cellular ATP synthesis, represented a most important observation (19). It suggested that an extracellular species could influence the rate of intracellular metabolic events. Confirmation and extension of these studies linking intracellular ATP synthesis with extracellular ferricyanide reduction were then published $(2,20)$. Arese et al. (21) compared the effect on RBC glycolysis of the impermeant species ferricyanide to that of pyruvate, an oxidant which enters the cell, increases the NAD:NADH ratio, and thereby activates the enzyme G3PD. They observed that although ferricyanide was unable to penetrate the cell membrane, it resulted in a pattern of phosphorylated intermediates identical to that seen with pyruvate. They concluded that ferricyanide was, like pyruvate, able to oxidize NADH and thereby increase the activity of G3PD. These experiments coupled with our data from both intact cells and resealed ghosts strongly support the hypothesis that NADH generated at the G3PD reaction is the source of reducing equivalents for extracellular ferrocyanide generation. If NADPH has a

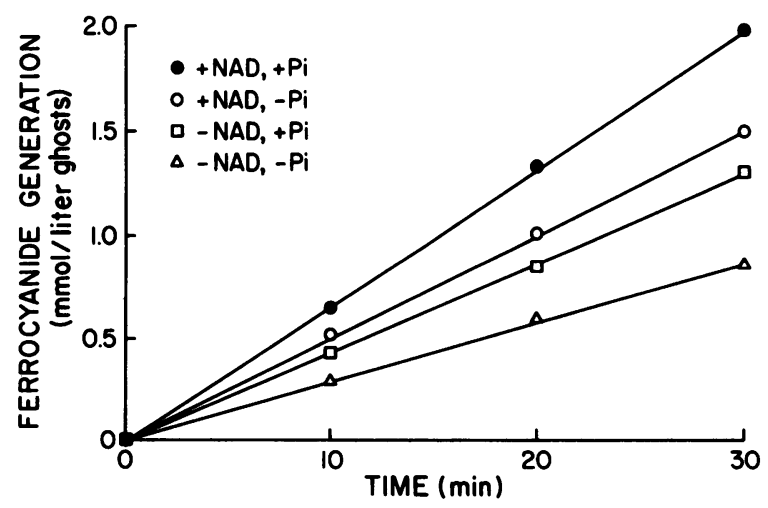

FIGURE 6 The effect of the omission of NAD and(or) Pi on the rate of ferrocyanide generation by resealed ghost preparations containing all other components of the NADH generating system. (DHA concentration $50 \mu \mathrm{M}$ ). 
TABLE III

Ferrocyanide Generation* by the Control $\ddagger$ or NADH-Containing $\$$ Ghost Systems in the Presence and Absence of DHA $(50 \mu M)$

\begin{tabular}{lcc}
\hline & \multicolumn{2}{c}{ DHA } \\
\cline { 2 - 3 } Ghost system & Minus & Plus \\
\hline Control & 0.29 & 0.82 \\
NADH & 0.48 & 3.81 \\
\hline
\end{tabular}

${ }^{*}$ Expressed as $\mathrm{mmol} / \mathrm{liter}$ ghosts $\cdot \mathrm{h}$.

$\ddagger$ ATP $0.5 \mathrm{mM}$.

§ ATP $0.5 \mathrm{mM}$, GSH $1.0 \mathrm{mM}$, NAD $0.25 \mathrm{mM}$, fructose diphosphate $0.5 \mathrm{mM}$, ADP $0.25 \mathrm{mM}$, nicotinamide $0.5 \mathrm{mM}$, aldolase $0.03 \mathrm{mg}$, G3PD $0.3 \mathrm{mg}$.

role in ferricyanide reduction, it must quantitatively be quite small because $\mathrm{O}_{2}$ consumption does not increase after ferricyanide exposure (2). Further, we have studied RBC from G6PD-deficient individuals (both mild and severe variants), all of whom generated ferrocyanide at normal rates.

Although the evidence implicating $\mathrm{NADH}$ as the primary source of reducing equivalents for ferrocyanide generation is rather convincing, the mechanism responsible for the transfer of electrons from NADH to ferricyanide is less certain. The demonstration of an $\mathrm{NADH}$ :ferricyanide oxidoreductase in RBC membrane preparation(s) initially suggested that an electron transfer apparatus existed as an integral part of the RBC membrane (22). Subsequent experiments have shown, however, that the oxidoreductase is localized to the inner face of the membrane (23). Its reducing equivalents were accessible to ferricyanide only when the membrane was disrupted, and its activity was inversely proportional to the physical integrity of the ghost preparation under study (23). Similar results were obtained when membrane preparations from Escherichia coli were examined $(24,25)$. In a more recent study with vesicles prepared from Bacillus subtilis, it could be demonstrated that although ferricyanide was inaccessible to the NADH dehydrogenase itself, it could receive electrons from other carriers of the respiratory chain (26). Of particular interest was the impaired electron transfer by vesicles prepared from mutants deficient in the vitamin $\mathrm{K}$ congener menaquinone. When these vesicles were supplied with the deficient vitamin, ferricyanide reduction was completely restored (26).

We have constructed a model to explain the mechanism of ferricyanide reduction as observed in human RBC (Fig. 7). DHA is known to penetrate the RBC membrane $(4,16,17)$, and once within the cell it is reduced to ascorbic acid $(4,15,27)$. Our data would suggest that the reduction involves the transfer of a hydrogen atom from NADH to DHA, a reaction also demon-

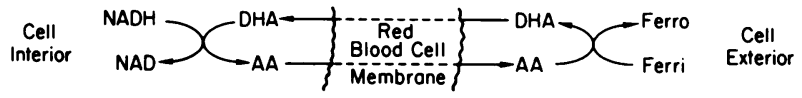

Figure 7 A model of the AA-mediated transmembranereducing system of the human $\mathrm{RBC}$.

strated by other investigators (27). From our experiments we cannot be certain whether the reducing equivalents pass directly from NADH to DHA or whether an additional carrier is involved. Although glutathione has been implicated in the reduction of DHA (15), its primary role could simply be to maintain the sulfhydryl groups of G3PD in the reduced form. Once formed, AA begins to leave the RBC at a constant rate (16), then becoming available for the nonenzymatic reduction of ferricyanide. The decline in the rate of ferricyanide reduction observed after the initial 20-30 min is also consistent with this hypothesis because DHA is an inherently unstable molecule. In an aqueous solution at neutral $\mathrm{pH}, 50 \%$ of the DHA present will decompose in $1 \mathrm{~h}$ (28). Its catabolism can be greatly accelerated by the presence of ferric iron (29). In fact, patients with iron overload demonstrate low AA levels (30) and an accelerated rate of AA catabolism (31).

Many similarities suggest that this transmembrane reducing system has a physiological role in the process of cellular iron accumulation. The uptake of iron by RBC precursors involves the binding of transferrin, a $\beta$-globulin which carries two atoms of ferric iron per molecule of protein, the release from transferrin of iron, and the transmembrane movement of iron into the cell (32). At some point between the binding of transferrin and the cellular uptake of iron, a reduction from the ferric to the ferrous state must occur (33). Many features suggest that the AA-mediated transmembrane-reducing system described above is responsible for this vital step in cell iron uptake. First, unlike the binding of transferrin which rapidly saturates all available sites, in vitro cell iron accumulation occurs in a linear fashion over $30 \mathrm{~min}$ (32). Second, a serum factor is known to enhance the rate of iron uptake by reticulocytes (34). Third, ascorbic acid is known to increase gastrointestinal iron absorption (35). Last, AA is known to promote the release of iron from reticuloendothelial deposits (36). Animals placed on a scorbutic diet develop a progressive fall in such iron-containing cellular constituents as the cytochromes and hemoglobin and a concomitant increase in the nonheme iron content of spleen and muscle (37). Studies are presently underway in our laboratory to explore the potential relationship between the AA-mediated transmembrane-reducing system and cellular iron accumulation.

\section{ACKNOWLEDGMENTS}

The authors wish to acknowledge the secretarial assistance of Fay Weaver and the invaluable suggestions and criticism of John C. Parker. 
This work was supported in part by a grant from the U. S. Public Health Service (AM 11356).

\section{REFERENCES}

1. Orringer, E. P., and M. E. S. Roer. 1978. An ascorbic acid mediated erythrocyte transmembrane reducing system. Clin. Res. 26: 354A. (Abstr.)

2. Mishra, R. K., and H. Passow. 1969. Induction of intracellular ATP synthesis by extracellular ferricyanide in human red blood cells. J. Membr. Biol. 1: 214-224.

3. Székely, M., S. Mányai, and F. B. Straub. 1952. Über den mechanismus der osmotischen hämolyse. Acta Physiol. Acad. Sci. Hung. 3: 571-583.

4. Stankova, L., D. A. Rigas, and R. H. Bigley. 1975. Dehydroascorbate uptake and reduction by human blood neutrophils, erythrocytes, and lymphocytes. Ann. N. Y. Acad. Sci. 258: 238-242.

5. Avron, M., and N. Shavit. 1963. A sensitive and simple method for determination of ferrocyanide. Anal. Biochem. 6: 549-554.

6. Bodemann, H., and H. Passow. 1972. Factors controlling the resealing of human erythrocyte ghosts after hypotonic hemolysis. J. Membr. Biol. 8: 1-26.

7. Schwoch, G., and H. Passow. 1973. Preparation and properties of human erythrocyte ghosts. Mol. Cell. Biochem. 2: 197-218.

8. Lowry, B. A., M. K. Williams, and I. M. London. 1962. Enzymatic deficiencies of purine nucleoticle synthesis in the human erythrocyte. J. Biol. Chem. 237: 1622-1625.

9. Orringer, E. P., and W. D. Mattern. 1976. Formaldehydeinduced hemolysis during chronic hemodialysis. N. Engl. J. Med. 294: 1416-1420.

10. Owen, J. A., and B. J. Iggo. 1956. The use of p-chloromercuribenzoic acid in the determination of ascorbic acid with 2:6 dichlorophenolindophenol. Biochem. J. 62: 675-680.

11. Sullivan, J. F., and A. B. Eisenstein. 1972. Ascorbic acid depletion during hemodialysis. J. Am. Med. Assoc. 220: 1697-1699.

12. Kopple, J. D., and M. E. Swendseid. 1975. Vitamin nutrition in patients undergoing maintenance hemodialysis. Kidney Int. 7(Supp. '2): 79-84.

13. Sullivan, J. F., and A. B. Eisenstein. 1970. Ascorbic acid depletion in patients undergoing chronic hemodialysis. Am. J. Clin. Nutr. 23: 1339-1346.

14. Loach, P. A. 1970. Oxidation-reduction potentials, absorbance bands, and molar absorbance of compounds used in biochemical studies. In Handbook of Chemistry. H. A. Sober, editor. The Chemical Rubber Co., Cleveland. 2nd edition. J-33-J-40.

15. Hughes, R. E. 1964 . Reduction of dehydroascorbic acid by animal tissues. Nature (Lond.). 203: 1068-1069.

16. Hughes, R. E., and S. C. Maton. 1968. The passage of vitamin $\mathrm{C}$ across the erythrocyte membrane. $\mathrm{Br}$. J. Haematol. 14: 247-252.

17. Mann, G. V., and P. Newton. 1975. The membrane transport of ascorbic acid. Ann. N. Y. Acad. Sci. 258: 243252.

18. Tsuboi, K. K., and K. Fukunaga. 1965. Inorganic phosphate and enhanced glucose degradation by the intact erythrocyte. J. Biol. Chem. 240: 2806-2810.

19. Mányai, S., and M. Székely. 1954. Die wirkung von natriumflorid und monojodessigsäure auf die glykilyse von menschlichen roten blutkorperchen. Acta Physiol. Acad. Sci. Hung: 5: 7-18.

20. Knight, A. B., and T. J. McManus. 1974. Stimulation of red cell metabolism by external ferricyanide. Evidence for transmembrane electron flow. Fed.Proc. 33: 1400. (Abstr.)

21. Arese, P., A. Bosia, and G. P. Pescarmona. 1975. Über die wirkung von ferricyanid auf glykilyse and 2,3-diphosphoglycerat-zyklus in menschlichen erythrocyten. In VII International Symposium Über Struktur und Funktion der Erythrozyten. S. Rapaport and F. Jung, editors. Akademie-Verlag, Berlin. 91-102.

22. Zamudio, I., and M. Canessa. 1966. Nicotinamideadenine dinucleotide dehydrogenase activity of human erythrocyte membranes. Biochim. Biophys. Acta. 120: 165-169.

23. Zamudio, I., M. Cellino, and M. Canessa-Fischer. 1969. The relation between membrane structure and NADH: (Acceptor) oxidoreductase activity of erythrocyte ghosts. Arch. Biochem. Biophys. 129: 336-345.

24. Weiner, J. H. 1974. The localization of glycerol-3-phosphate dehydrogenase in Escherichia coli. J. Membr. Biol. 15: 1-14.

25. Futai, M. 1974. Orientation of membrane vesicles from Escherichia coli prepared by different procedures. $J$. Membr. Biol. 15: 15-28.

26. Bisschop, A., J. Boonstra, H. J. Sips, and W. N. Konings. 1975. Respiratory chain linked ferricyanide reduction drives active transport in membrane vesicles from Bacillus subtilis. FEBS (Fed. Eur. Biochem. Soc.) Lett. 60: $11-16$.

27. Weis, W. 1975. Ascorbic acid and electron transport. Ann. N. Y. Acad. Sci. 258: 190-200.

28. Tolbert, B. M., M. Downing, R. W. Carlson, M. K. Knight, and E. M. Baker. 1975. Chemistry and metabolism of ascorbic acid and ascorbate sulfate. Ann. N. Y. Acad. Sci. 258: 48-69.

29. Taqui Khan, M. M., and A. W. Martell. 1967. Metal ion and metal chelate catalyzed oxidation of ascorbic acid by molecular oxygen. I. Cupric and ferric ion catalyzed oxidation. J. Am. Chem. Soc. 89: 4176-4185.

30. Wapnick, A. A., T. H. Bothwell, and H. Seftel. 1970. The relationship between serum iron levels and ascorbic acid stores in siderotic bantu. Br. J. Haematol. 19: 271-276.

31. Lynch, S. R., H. C. Seftel, J. D. Torrance, R. W. Charlton, and T. H. Bothwell. 1967. Accelerated oxidative catabolism of ascorbic acid in siderotic bantu. Am. J. Clin. Nutr. 20: 641-647.

32. Morgan, E. H., and E. Baker. 1969. The effect of metabolic inhibitors on transferrin and iron uptake and transferrin release from reticulocytes. Biochim. Biophys. Acta. 184: 442-454.

33. Morgan, E. H. 1974. Transferrin and transferrin iron. In Iron in Biochemistry and Medicine. A. Jacobs and $M$. Worwood, editors. Academic Press Inc. Ltd., London. 30-71.

34. Workman, E. F., G. Graham, and G. W. Bates. 1975. The effect of serum and experimental variables on the transferrin and reticulocyte interaction. Biochim. Biophys. Acta. 399: 254-264.

35. Glover, J. M., P. R. Jones, D. A. Greenman, R. E. Hughes, and A. Jacobs. 1972. Iron absorption and distribution in normal and scorbutic guinea-pigs. Br. J. Exp. Pathol. 53: 295-300.

36. Lipschitz, D. A., T. H. Bothwell, H. C. Seftel, A. A. Wapnick, and R. W. Charlton. 1971. The role of ascorbic acid in the metabolism of storage iron. Br. J. Haematol. 20: 155-163.

37. Degkwitz, R., S. Walsch, M. Dubberstein, and J. Winter. 1975. Ascorbic acid and cytochromes. Ann. N. Y. Acad. Sci. 258: 201-207. 